\title{
Modelling a Lignite Power Plant in Modelica to Evaluate the Effects of Dynamic Operation and Offering Grid Services
}

\author{
M. Hübel ${ }^{2}$, A. Berndt ${ }^{2}$, S. Meinke ${ }^{1}$, M. Richter ${ }^{2}$, P. Mutschler ${ }^{2}$, \\ E. Hassel ${ }^{2}$, H. Weber ${ }^{2}$, M. Sander ${ }^{2}$, J. Funkquist ${ }^{1}$ \\ ${ }^{1}$ Vattenfall Research and Development \\ Otternbuchtstrasse 14-16, 13599 Berlin, Germany \\ ${ }^{2}$ University of Rostock \\ A.-Einstein-Str. 2, 18059 Rostock, Germany \\ $<$ sebastian.meinke@vattenfall.de> <moritz.huebel@uni-rostock.de>
}

\section{Abstract}

Offering services to stabilize the electrical grid is nowadays one of the major tasks of fossil power plants and also of significant economical relevance. However the effects on the power plants regarding the additional wear of components is uncertain. Usually the effects regarding control reserves, especially primary control occur with high frequencies and small amplitudes, which makes investigations based on measurement data impossible since the effects are masked by the noise of normal operation. In order to investigate this issue, a detailed model of a lignite power plant has been used, which was developed in Modelica for simulating and comparing scenarios with and without offering primary control reserves. The model comprises the entire water-steam cycle including turbines, preheaters and pumps, as well as a very detailed boiler model including the air supply, coal mills, a combustion chamber, heating surfaces and piping. Furthermore the power plants control system has been implemented in a very precise way. In addition the study involves an investigation on the input signals (grid frequency) and a calculation of lifetime consumption for specific components to evaluate the effects.

Keywords: Power Plant, Dynamic Modelling, Control Reserves, Primary Control, Lifetime Consumption

\section{Introduction}

In addition to the mere production of electrical energy, many fossil power plants are needed to provide control services, which are necessary to operate the electrical grid. In order to stabilize the frequency of the electrical grid, the consumption has to be compensated by the production at any moment. In order to guarantee this, it is required to activate or deactivate power production within seconds. The control reserves can be categorized within three corresponding grid services - primary control, secondary control and tertiary control as described in [5]. Although the necessity of granting grid services is undisputed, the consequences for fossil power plants are still uncertain. As the market for the mere production of electrical energy is declining for conventional plants, offering grid services (e.g. primary control reserves) gets more and more relevant. In order to investigate the dynamic effects on a lignite power plant, a method is presented which uses the dynamic simulation of a complex lignite fired power plant in Modelica. Similar models of a hard coal fired power plant and a combined cycle gas turbine power plant have been developed previously for different applications (e.g. [1], [2] and [3]). The dynamic model enables the user to calculate pressures and temperatures in various locations of the power plant and therefore computing mechanical and thermal stress in specific components. The results will be used to derive lifetime consumption and evaluate the effects of offering grid services, e.g. primary control reserves for this power plant. 


\section{Primary Control Requirements}

The setpoint of the frequency in the European grid system is $50 \mathrm{~Hz}$. The allowed variation of the mains frequency in normal mode is between $49.8 \mathrm{~Hz}$ and $50.2 \mathrm{~Hz}$. If a failure occurs on the consumer or producer side the frequency can change within a few seconds. The primary control counteracts this. In figure 1, a typical trend for the mains frequency of one day is shown.

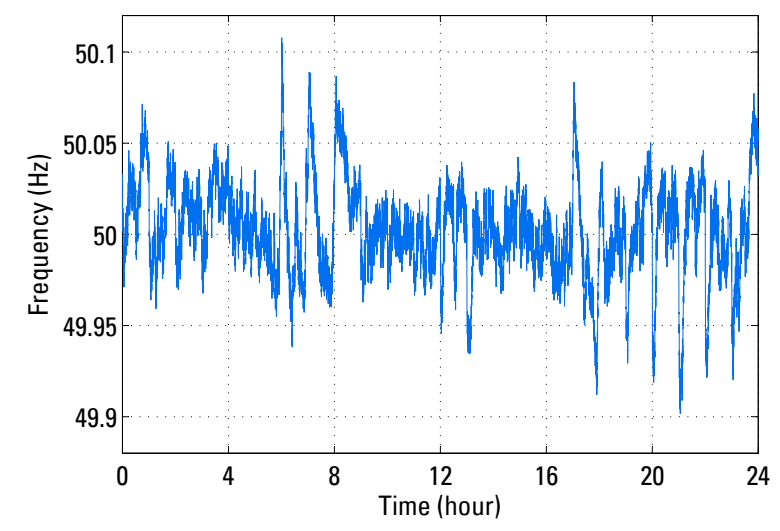

Figure 1: Trend of mains frequency of one day

Every power plant involved in the primary control has to provide at least $2 \%$ of its effective power as primary control reserve, which has to be available within $30 \mathrm{~s}$.

The dynamical behavior of a power plant is dominated by the dynamics of the steam generator and turbine. In order to provide additional electrical power in a short period of time, needed for primary control, different modes exist:

- Throttling of HP/IP-valve: The power plant operates in all operating points with throttled high and intermediate pressure steam valves. This grants that the power plant can increase its output by opening the valves for a positive output demand and decrease its output by increasing the throttling of the valves.

- Low pressure preheater bypass: In this mode the power plant increases its electrical output by throttling the valves to the low pressure preheaters and the feedwater tank. In order to avoid thermal stress in the low pressure preheaters the speed of the condensate pump is decreased. The whole process leads to more steam in the turbine stages and thus to more electrical output. The limits of this mode are the filling levels of the condenser and the feedwater tank. For a negative power demand the HP/IP steam valves are throttled as described in the previous point.

- High pressure preheater bypass: This mode is the same like the low pressure preheater bypass but uses the high pressure preheaters and the feedwater pump instead.

In order to investigate the influence of the primary control for a whole year, it is possible to simulate the whole year with the mains frequency as a model input, but it takes a lot of time. The implemented model has a ratio of real time to simulated time of about 1:1 to $1: 10$. Thus the simulation of one year would take at least one and a half month. In order to reduce simulation time the data of the mains frequency is analyzed and subdivided into characteristic signals, distinguishing between:

- changes in mains frequency, which occur every full hour, because of the changes of the power plants schedules

- noise due to the fluctuating consumer load

- power plant outage due to technical issues

These different signals will be extracted and analysed from the mains frequency data of one year. In the following, the changes in mains frequency every full hour are explained in more detail, because they have the highest amplitudes of all the characteristic signals. The basic strategy is to cut out the time data of the mains frequency and to classify these signals. Afterwards all signals in one class are averaged in order to get one signal for every class. For this purpose it must be ensured that the extremum of all the signals in one class are situated at the same time. This is realized by extracting the signals \pm 5 minutes around the extremum, which can be in an interval of +7.5 minutes after every full hour. Figure 2 shows all signals belonging to class 1 , which contains such mains frequency changes of the year 2011 with amplitudes between $-0.14 \mathrm{~Hz}$ and $-0.105 \mathrm{~Hz}$. Furthermore the averaged signal is shown. In order to consider the different intervals $t n$ between the extremum and the full hour, this value is allocated to every extracted and classified signal. All signals in one class of amplitude are different in $t n$. An average $t n$, mean is calculated in order to avoid a multiplicative increase of simulation scenarios. 


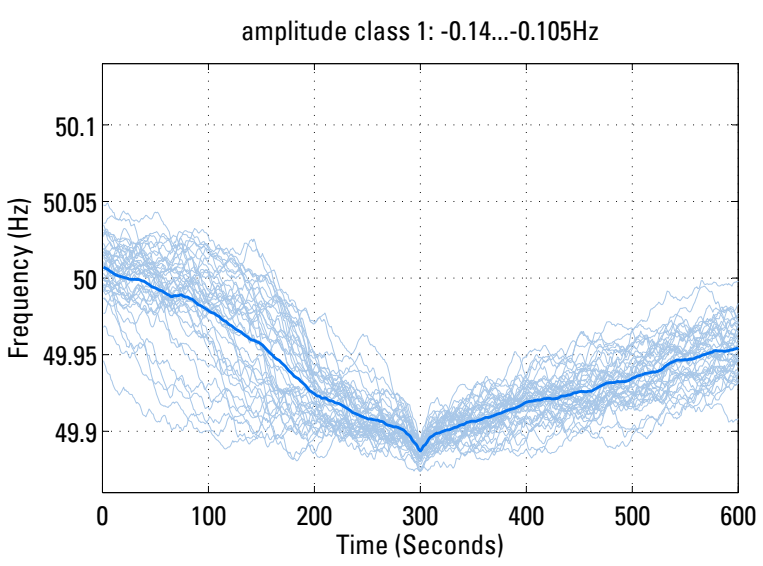

Figure 2: All signals of one class with the averaged signal in dark blue

The averaging of all mains frequency signals in one class minimizes the noise. In order to consider this noise a characteristic noise signal is added to the averaged signals of changes in mains frequency every full hour. The results of the classification are eight frequency signals for the changes of frequency every hour which are shown in figure 3 . The eight frequency signals are considered as rep-

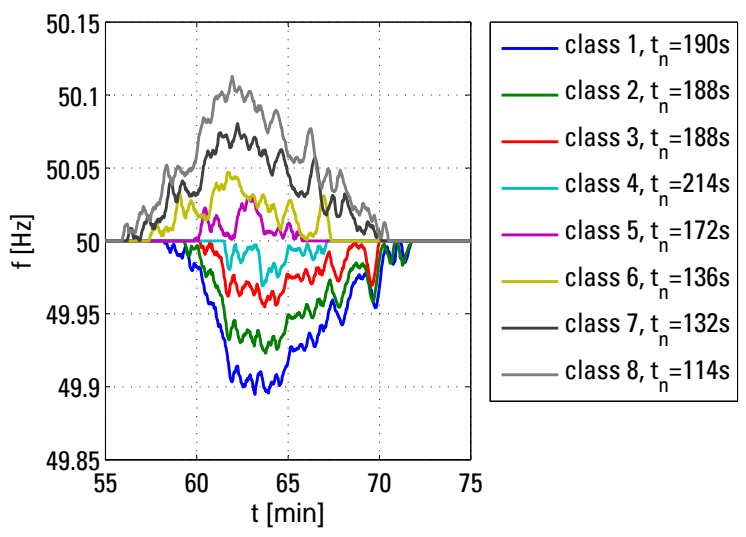

Figure 3: Scenarios of mains frequency changes which occur after every full hour. The extremum is situated $t_{n}$ seconds after the full hour.

resentative inputs for subsequent investigations for all power plants participating in primary control in the ENTSO-E grid.

\section{Power Plant System Model}

\subsection{Reference Power Plant}

The investigated power plant is a duo-block lignite power plant as shown in figure 4 . Each of the blocks has two boilers, which provide steam

\begin{tabular}{|l|c|c|}
\hline & Mono & Duo \\
\hline Gros el. Output & $265 \mathrm{MW}$ & $530 \mathrm{MW}$ \\
Load Gradient & $4 \mathrm{MW} / \mathrm{min}$ & $8 \mathrm{MW} / \mathrm{min}$ \\
Primary Control & $12.5 \mathrm{MW}$ & $25 \mathrm{MW}$ \\
\hline
\end{tabular}

Table 1: Reference data of the Duo-Block Plant

for a mutual turbine. The block can be operated with both boilers (duo-operation) or using only one (mono-operation). One turbine has an electric output of about 530 MW. Coming from the turbine, the steam is condensed in two parallel condensers. Afterwards there is one common line of four low pressure preheaters. Then, the flow splits up for two feedwater tanks and parallel feedwater pumps and three high pressure preheaters. From there the flow enters the boilers. The boilers are using a forced circulation for the evaporation part and are equipped with parallel lines in the superheater section.

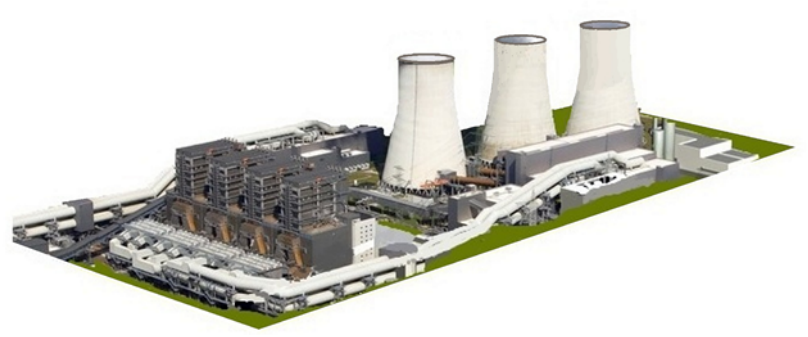

Figure 4: Investigated reference power plant

The investigated plant currently operates in base load, producing a significant amount of electrical energy. In addition to that, it offers considerable amounts of control reserves, especially primary control reserves, see Table 1 for reference data.

\subsection{Dynamic Process Model}

The dynamic model has been built within Dymola using the open programming language "Modelica". The components used to build the model are mainly based on the "ThermalPower Library" developed by Modelon AB.

As the block arrangement in the real plant, the dynamic model consists of several components involving a diversity of different physics. An overview is given in figure 5 . The general approach for all models involves the balance equations for mass and energy as well as a simplified momentum 


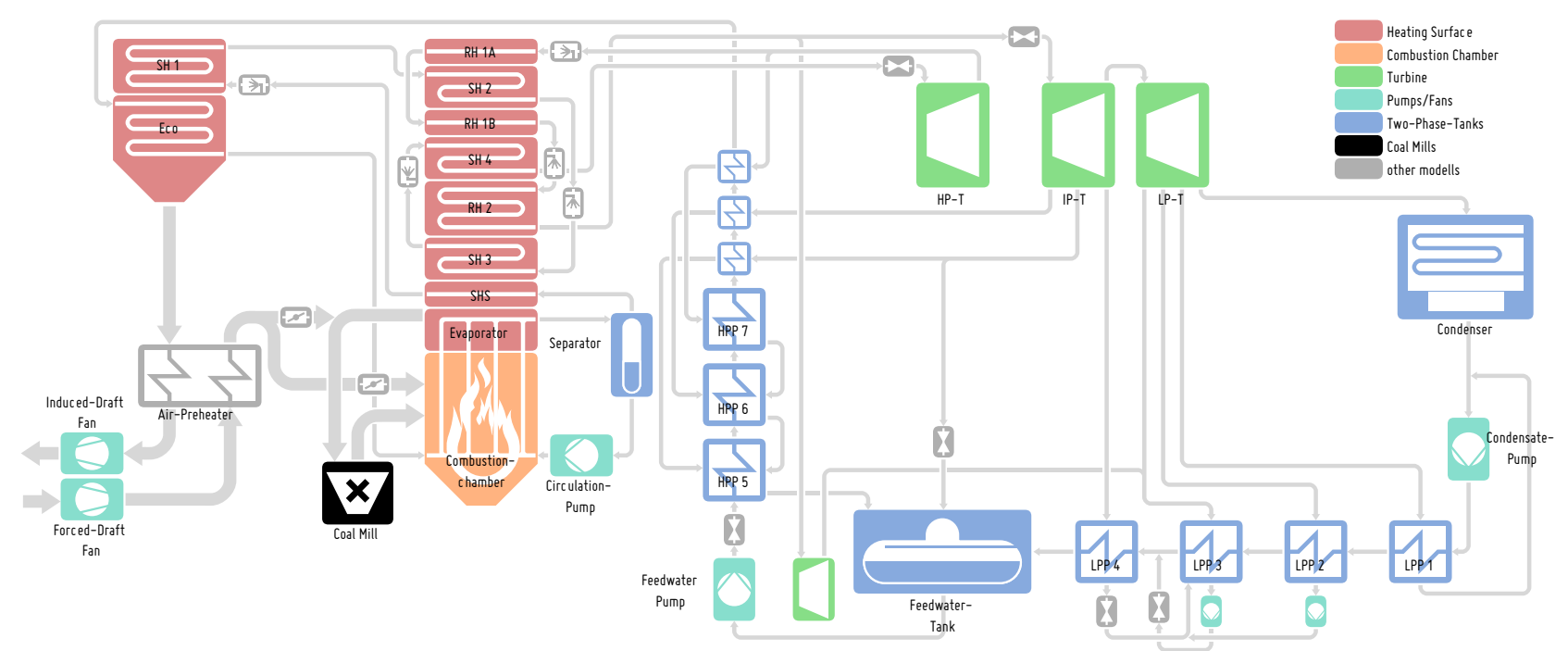

Figure 5: Implemented components of reference power plant

equation to calculate pressure drops. Using these equations as well as specific heat transfer assumptions for conduction, convection and radiation and the fluid properties for the involved mediums (flue gas, water) a power plant process can be described on a fundamental basis. A detailed explanation of physical backgrounds for all the basic models used here can be found in [6]. However the complex power plant system required some more sophisticated models which needed to be developed in order to reproduce the plants behaviour in an accurate way. One example for such a component is the lignite coal mill as presented in figure 6 . The coal mill is not only responsible for grinding the coal to the desired size, but also for drying the lignite, as the water content of the fuel is usually between 50-60\%. As those effects have a significant impact on the overall process dynamics, a model had to be developed to describe the dynamic behaviour of the coal mills.

The coal mill model consists of three main paths. The gas path describes the hot flue gas which is recirculated from the combustion chamber. Furthermore fresh air with lower temperature is added to control the temperature in the classifier of the mill. The ventilation effect of the mill is represented by a simple fan model based on the specific characteristic of the mill. The water path represents the water content of the coal which is evaporated in the mill. The energy used for evaporation is taken from the hot flue gas. After evaporation, the water is mixed with the flue gas. The coal containing a residual water content of $10-20 \%$ is represented by the coal path.

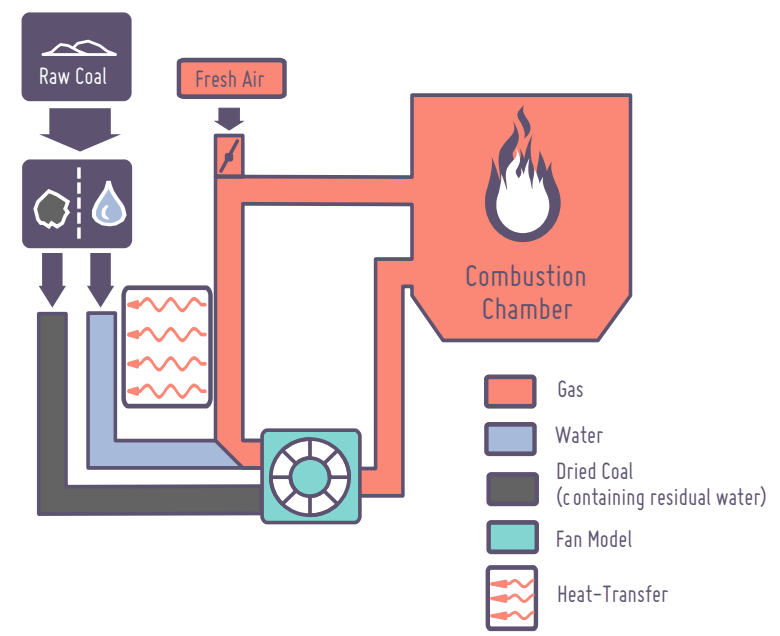

Figure 6: Schematic of the lignite coal mill model

One essential part of the model is the changed lower caloric heating value due to the evaporation of the water. In order to describe this, a simple assumption based on [7] leads to reasonable results:

$C V_{x}=\frac{C V_{0}}{\left(1-X_{A, 0}\right)\left(1-X_{W, 0}\right)}\left(1-X_{A, x}\right)\left(1-X_{W, x}\right)$

Wherein $C V$ denotes the lower caloric heating value and $X$ the mass content of a specific component (index $A$ for ash, $W$ for water). The indices $x$ and 0 are representing the state before and behind the evaporation stage. The delay time for 
the grinding of the coal has been identified by fitting the heat release to the measurement data. [8] gives some values for the delay time in each stage of the mill, which gives a reasonable starting point for this optimisation procedure. The water steam cycle has been adapted to a single boiler. For the model, components which are actually used by both boilers are represented as a symmetric part with the half size. This concerns the models for the steam turbine, as well as the low pressure preheater line.

\subsection{Control System}

For making simulation-based statements about the influence of different power plant operation modes the thermodynamic model is coupled to a reduced copy of the origninal power plant control system, which is implemented using the Modelica Standard Library components. The implemented control system uses the currently calculated physical values (i.e. live steam parameter, generated power at a specific coal input) and in a consequence adjusts set values (e.g. life steam pressure) and manipulated variables (e.g. position of the feed water valve) for the water-steam cycle. Because of this feedback the accuracy and the level of details of the modelled processes needs to be reasonably high. Figure 7 is showing the hierarchical structure of the control system, which has been coupled to the process model.

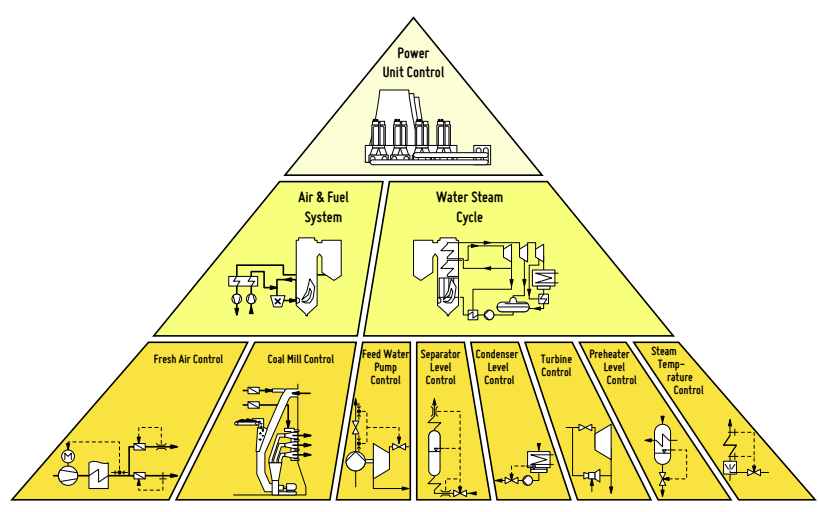

Figure 7: Overview on the control loops implemented in the model

Of particular interest is the Power Unit control which processes the incoming power and control reserve requests to a corresponding desired firing power. In detail the power plant control system sets the firing power using a map based pilot control. The expected electric power output is pre- dicted by a transfer function based model of the firing process and the heat transfer in the boiler. The difference between this predictive value and the corresponding measurement is adjusted via a corrective control loop, as described in the VDI/VDE guideline 3508 [9]. Due to the slow transient response of the firing process, fast changes in the power output, as requested for primary control reserve, could only be conducted by using the steam storage of the boiler by altering the pressure set point until the firing process could catch up. The extracted energy needs to be filled up with a temporarily over steered firing set point. In case of negative primary control request the pressure set point is increased until the steam production of the boiler could be reduced. By undershooting the firing power the stored steam mass could be discharged, while holding the desired electric power set point. This functionality is shown in figure 8 .

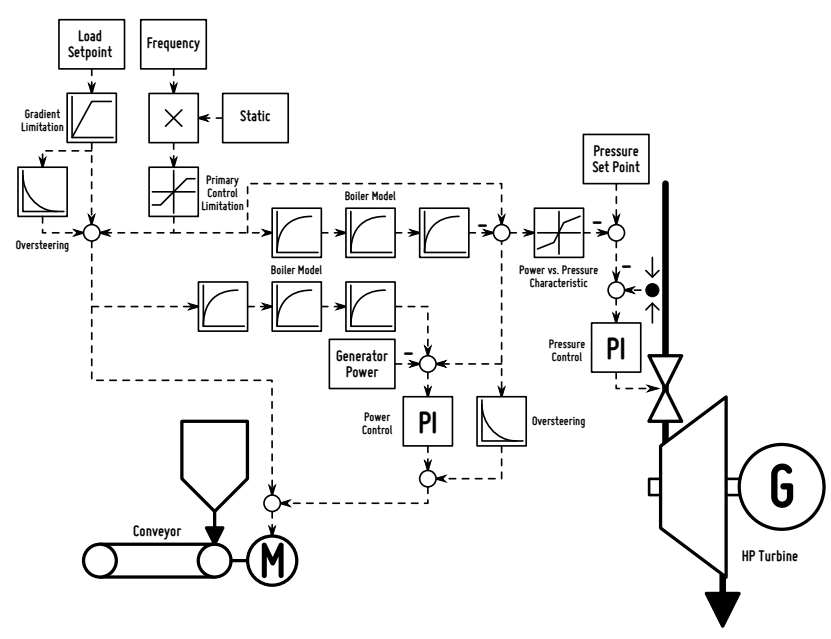

Figure 8: Schematic of the Power Unit Control

\subsection{Validation of the Model}

In order to validate the model, a scenario has been simulated covering the entire load range of the power plant from minimum load to nominal load. As required by the primary control investigation, the model has been operated in duo-operation, assuming both boilers in synchron operation.

In the model as well as in the power plant, the electrical gross output is controlled. Figure 9 shows the input schedule (green) which is used in both - the model and the real plant. The generator output (blue) is shown for the simulation (light color) and for the measurement (dark color). As in the real plant, one of the five mills in operation 


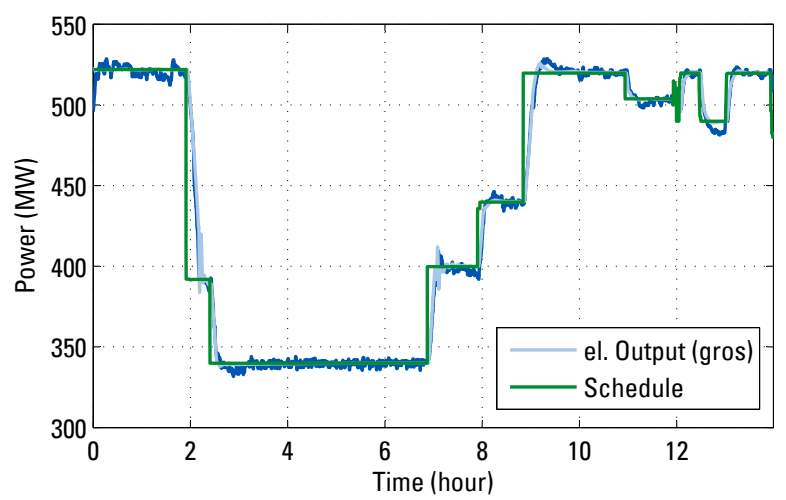

Figure 9: Schedule of the reference scenario (green), validation of power output (measurement dark blue, simulation light blue)

is shut down in very low load (at about $2.5 \mathrm{~h}$ ), this mill is returning into operation at about $7 \mathrm{~h}$, causing highly dynamic effects on the entire system. As can be seen from the plot, the simulated power generation fits the measurement not only in steady state points, but also for ramps and most of the dynamic oscillations.

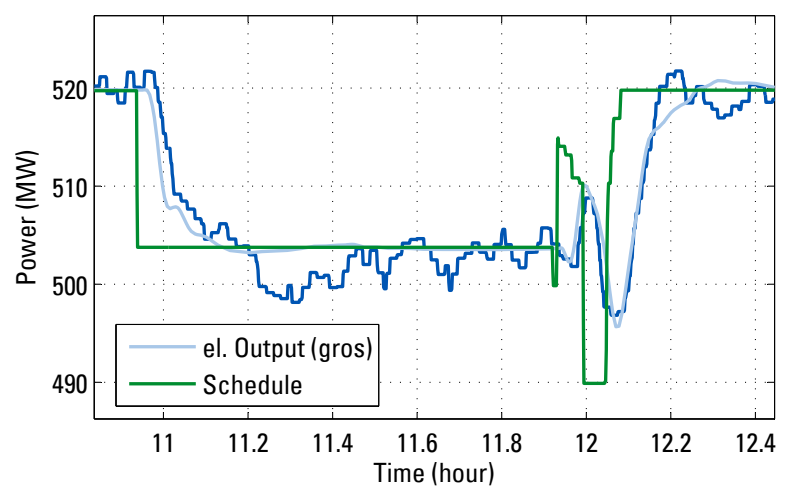

Figure 10: Zoomed validation of power output (schedule green, measurement dark blue, simulation light blue)

In figure 10 a zoomed validation plot from the reference scenario is presented. In this detailed view, setpoint-changes with amplitudes and timescale of primary control activation is shown. It can be concluded that the models really accuratly represents the power plants behaviour at fast setpoint-changes. However some effects like the steady state offset between $11.2 \mathrm{~h}$ and $11.8 \mathrm{~h}$ cannot be reproduced. A reason for that might be a changing caloric heating value of the coal in the power plant which is assumed to be constant in the model.

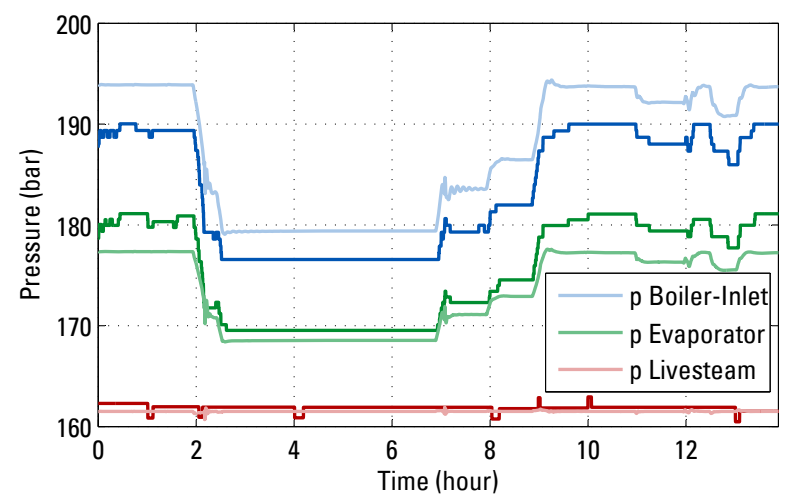

Figure 11: Validation of boiler pressure (measurement dark, simulation light)

In Figure 11 pressures from the water-steam cycle are presented. The live steam pressure (red line) is controlled by the turbine valve to a constant value of 162 bar for the entire operation range. The pressure at the evaporator and the entry of the boiler are calculated by the model based on the pressure drop of the integrated components. As can be seen from the figure, this pressure drop is highly dependent on the load, because the flow of the steam changes accordingly. Comparing measured and simulated pressures, the model shows a high agreement regarding the pressure levels.

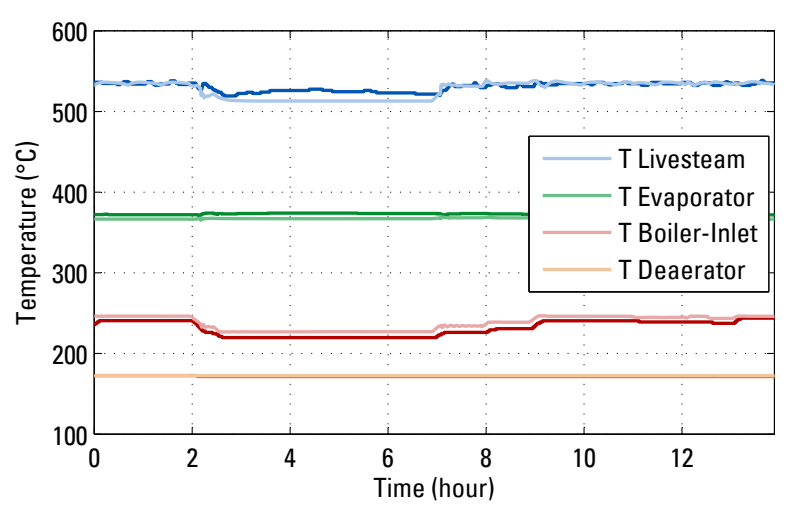

Figure 12: Validation of the temperatures (measurement dark, simulation light)

In Figure 12 some of the process temperatures are compared to the measurement data. The temperature in the deaerator is controlled to $174^{\circ} \mathrm{C}$ for the entire operation range. The temperature of the boiler-inlet is manly dependent on the heat transfer in the high pressure preheaters. The temperature level in the evaporator is dependent on the pressure level, as there are two-phase conditions. The livesteam temperature is being controlled by 
the spray attemperators, however in very low load (between 2.5 and $7 \mathrm{~h}$ ) the steam temperatures drop due to a shifting distribution of heat flux in the boiler and are out of their controlled range.

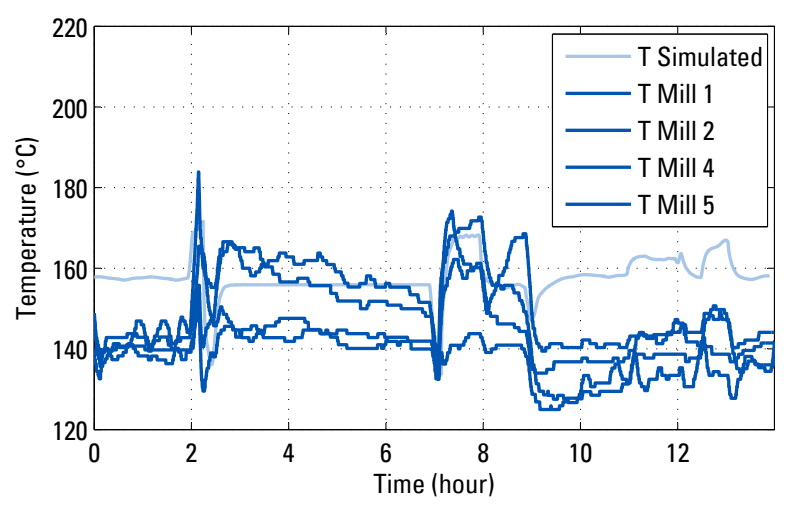

Figure 13: Validation of the coal mill model (measurement dark, simulation light)

A validation of the coal mill model based on the classifier temperatures is being presented in Figure 13. This temperature is very sensible as it represents the mixture of very hot recirculated flue gas from the combustion chamber, preheated fresh air and coal entering from ambient conditions. The simulated temperature is based on an aggregated mill model, which represents all the mills in operation, being able to switch on or off separate mills by changing the fan characteristics. The model is therefore being compared to all the mills which are permanently in operation for this scenario. It can be observed, that the average dynamic behaviour of the mill is represented quite well.

After an extensive validation based on measurement data, the dynamic model is used to calculate temperatures and pressures in critical components, thus enabling a calculation of thermal and mechanical stress according to structural mechanical approaches which are necessary derive lifetime consumption for specific simulation scenarios.

\section{Structural Mechanics}

The primary and secondary control leads to an increased number of load cycles of pressure and temperature changes within the power plant. As a result the fatigue of a component becomes more important than the creep fatigue. Particularly thickwalled pressurized components are affected by this cyclic loading. For this reason, a routine in Matlab was developed in accordance with DIN EN 12952 [4], to determine the component stress and the lifetime until the detectable cracklength is reached. Figure 14 shows the schematic workflow of the lifetime determination until the detectable crack inititiates.

Based on the pressure and temperature gradients the occurring stresses are determined in a first step. The mechanical stress $\sigma_{\text {tang } \mathrm{p}}$ is calculated with the boiler formula as follows.

$$
\sigma_{\text {tang } \mathrm{p}}=\left\{\begin{array}{cc}
\alpha_{\mathrm{m}} \cdot \frac{d_{\mathrm{ms}}}{2 \cdot e_{\mathrm{ms}}} \cdot p & \text { cylindrical shells } \\
\alpha_{\mathrm{sp}} \cdot \frac{d_{\mathrm{ms}}}{4 \cdot e_{\mathrm{ms}}} \cdot p & \text { spherical shells }
\end{array}\right\}
$$

In addition to the pressure difference between internal and external pressures, the notch factors $\alpha_{\mathrm{m}}$ and $\alpha_{\mathrm{sp}}$ are considered. The notch factor depends on the geometry of the cylindrical shell and of the pipe nozzle. The thermal stress $\sigma_{\mathrm{ws}}$ is calculated from the temperature difference $\Delta T$ between the two extreme values of the temperature-time function, the material factor $\Phi_{\mathrm{ws}}$ and the notch factor $\alpha_{T}$ according to the following equation:

$$
\sigma_{\mathrm{ws}}=-\Phi_{\mathrm{ws}} \cdot \Delta T \cdot \alpha_{T}
$$

The material factor contains the elastic modulus, the Poisson's ratio and the coefficient of thermal expansion. The total stress is generated by superposition of the mechanical and thermal stress and subsequently counted with the rainflow counting [10].

In a next step, the damage $\Delta S_{i}$ is calculated for each cycle (red frame in figure 14). For this, the cycles is converted to an $R$-ratio of $R=-1$ using the Gerber parabola and then multiplied with a roughness coefficient and a temperature coefficient. By adding up each part the amount of damage could be obtained.

\section{$5 \quad$ Results}

In the following the results for the "class 1 " scenario described in section 2 are shown. In order to investigate the influence of primary control on the life time reduction, a minus $25 \%$ load change with and without primary control are compared with each other.

The strongly stressed components are the thickwalled outlet headers. Therefore, the headers at 

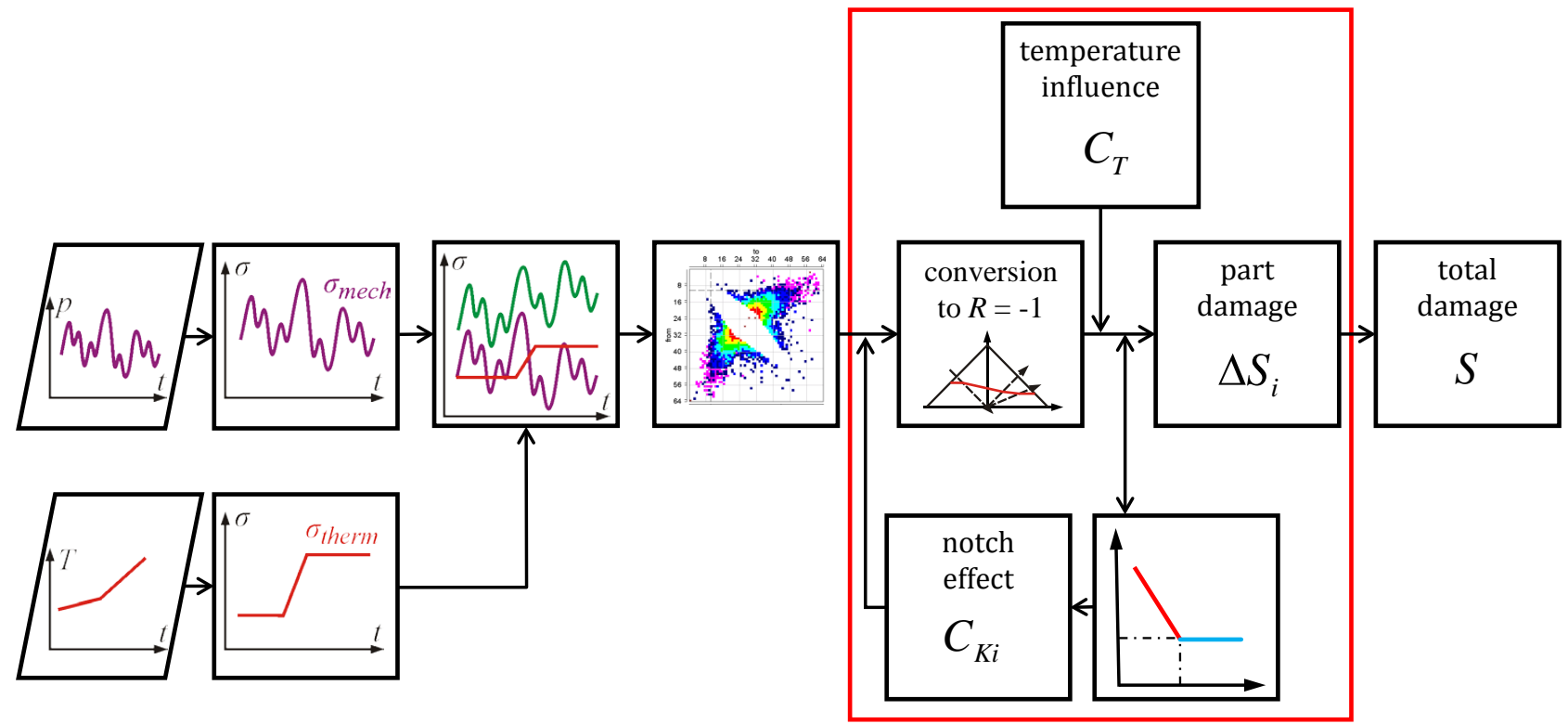

Figure 14: Schematic workflow of the lifetime determination

the outlets of superheater 4 and reheater 2 are considered first. Figure 15 shows the simulated pressure and temperature changes for the header of reheater 2. The solid lines represent the reference,
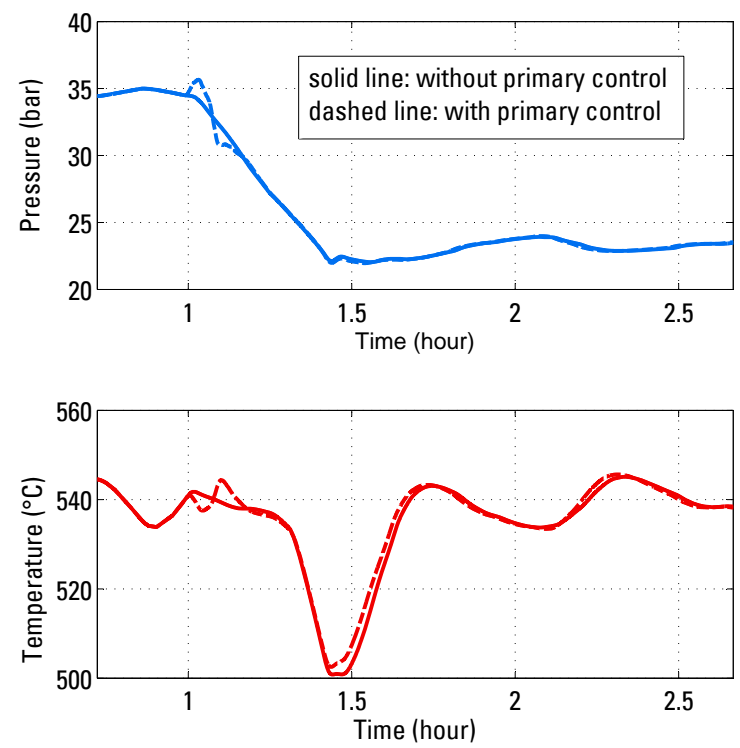

Figure 15: Simulation results for pressure and temperature of the steam in the header of reheater 2 .

which is the load change without primary control, the dashed ones represent the scenario with the primary control demand. In the first 10 minutes after the load change at $t=1 \mathrm{~h}$, in both pressure and temperature, the influence of the primary con- trol can be seen. In temperature the impact persists longer. The entire temperature response is affected and in fact the total minimum is higher for the case without primary control.

For the specific geometry of the reheater header the mechanical, thermal and total stresses are calculated as described in section 4 and the results are shown in figure 16 . While the mechanical

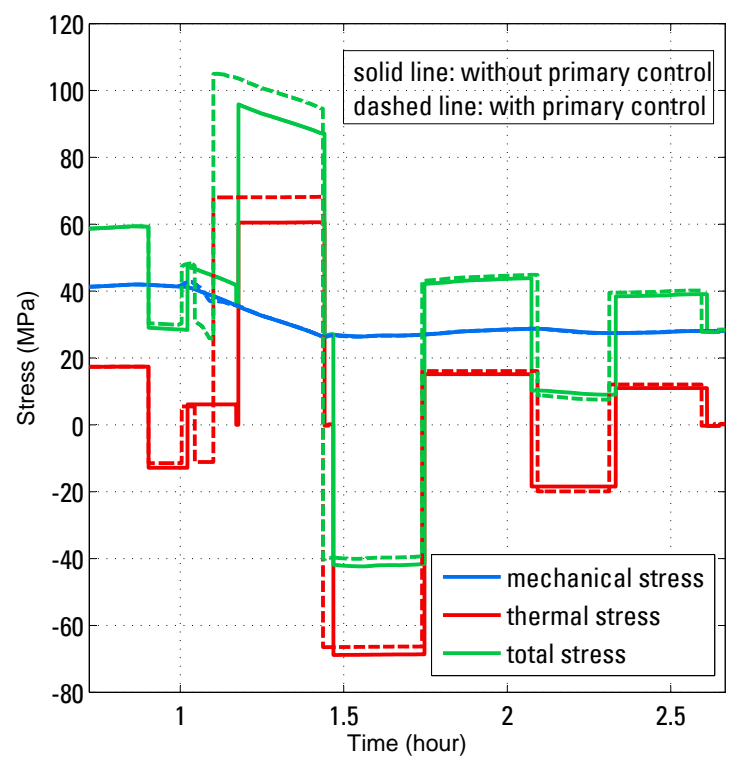

Figure 16: Mechanical, thermal and total stresses for the outlet header of reheater 2 (geometry of a cylindrical shell with a pipe nozzle). 
stresses are nearly the same, the thermal stresses show a small difference due to primary control and therefore also the total stresses. In order to calculate lifetime consumption, the continuous dynamic processes have to be partitioned into discrete load cycles. Therefore the method of rainflow-counting is used as described in the previous section. The outcome is shown in figure 17 for the header of reheater 2. The red line represents the limit for the

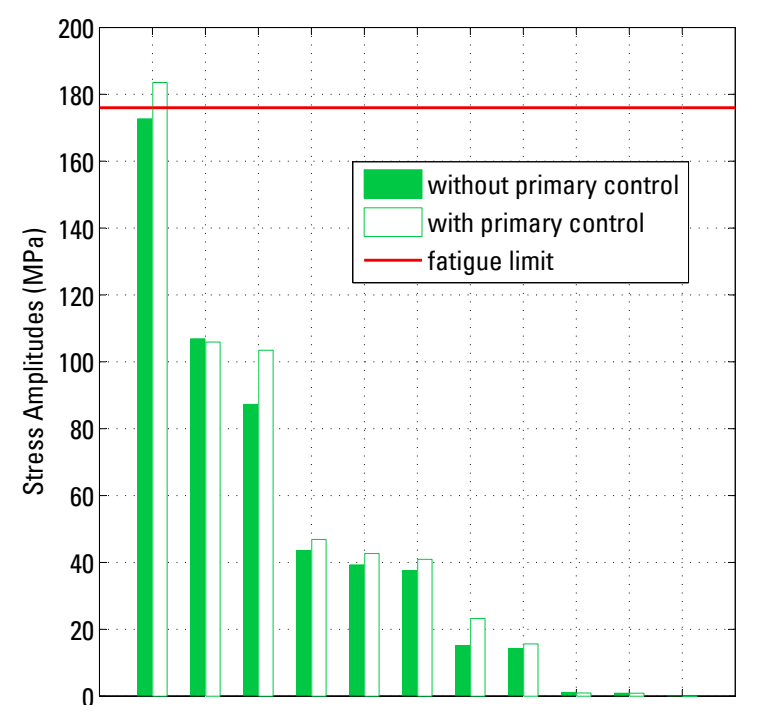

Figure 17: Sorted stress amplitudes of the outlet header of reheater 2 and the fatigue limit for this component for the scenario without and with a primary control demand.

fatigue. Obviously this fatigue limit is exceeded for the header of reheater 2 in the case of the primary control scenario. The corresponding damage $\Delta S$ is $1.3 \cdot 10^{-8}$, which is determined with the $\mathrm{S}$ N-curve (Wöhler curve) of the header material. In the case of the reference scenario without primary control the amplitudes are smaller and the fatigue limit is not exceeded.

For the same scenarios the stress amplitudes of the outlet header of superheater 4 are presented in figure 18. Here a damage occurs for both cases without and with primary control and is about $1.4 \cdot 10^{-6}$ and $6.8 \cdot 10^{-7}$, respectively. In contrast to reheater 2 the primary control scenario leads to smaller stress amplitudes than the pure load change.

In conclusion the results show that the impact of primary control on the life time reduction is not only determined by the pressure and temperature conditions but also strongly depends on the

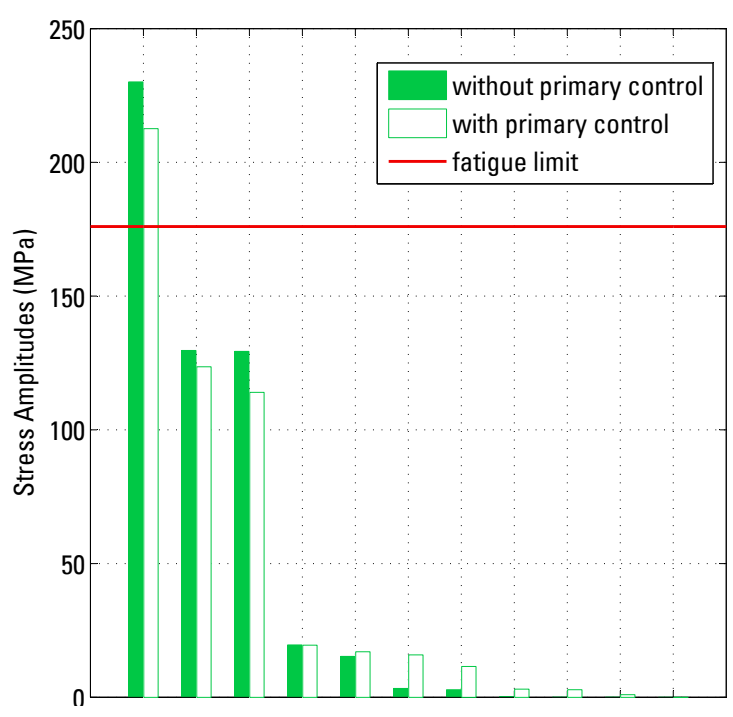

Figure 18: Sorted stress amplitudes of the outlet header of superheater 4 and the fatigue limit for this component.

geometry of the component. Thus the structural mechanics calculations need to be done for all components of the power plant. Furthermore, several scenarios have to be investigated and connected with their annual occurrence to identify the overall damage of the power plant due to primary control.

\section{Summary}

A very comprehensive dynamic model of a lignite fired power plant has been developed as presented in this paper. The model allows a diversity of applications focussing on dynamic operation e.g. control optimisation, calculation of lifetime consumption or energetic optimisation. One example application is the ongoing investigation on the impact of primary control on this power plant. The result of a fist scenario has been presented and explained on the example of two highly stressed components. In the next stages of this investigation, all the scenarios presented in section 2 will be simulated and multiplied with the share of their appearance in order to assess the overall impact of primary control.

\section{Acknowledgement}

The authors would like to thank VGB PowerTech and Vattenfall for providing financial support and input data as well as the participating delegates for 
inspiring discussions and helpful hints from practical experience during the project meetings. Also we would like to thank all the people at the power plant for supporting the acquisition of design and process data.

\section{References}

[1] Meinke, S., Gottelt F., Müller, M., Hassel E., Modeling of Coal-Fired Power Units with ThermoPower focussing on Start-Up Processes, 8th Modelica Conference, Dresden 2011

[2] Brunnemann, J., Gottelt, F., Wellner, K., Renz, A., Thüring, A., Roeder, V., Hasenbein, C., Schulze, C., Schmitz, G., Eiden, J., Status of ClaRaCCS: Modelling and Simulation of Coal-Fired Power Plants with CO2 Capture, 9th Modelica Conference, Munich, 2012

[3] Meinke, S., Modellierung thermischer Kraftwerke vor dem Hintergrund steigender Dynamikanforderungen aufgrund zunehmender Windenergie- und Photovoltaikeinspeisung, Dissertation, Rostock, 2012

[4] DIN EN 12952-3 Wasserrohrkessel und Anlagenkomponenten - Teil 3: Konstruktion und Berechnung für drucktragende Kesselteile. Deutsche Fassung EN 12952-3, 2011.

[5] TransmissionCode 2007 Netz- und Systemregeln der deutschen Übertragungsnetzbetreiber, Verband der Netzbetreiber, 2007

[6] Thermal Power Library Documentation, Modelon, 2013

[7] O'Kelly, P., Computer Simulation of Thermal Plant Operations, Springer, 2013

[8] Effenberger, H., Dampferzeugung, Springer 2000

[9] VDI/VDE-Guideline 3508, Unit control of thermal power stations, VDI/VDE, 2003

[10] Matsuishi, M., Endo, T., Fatigue of metals subjected to varying stress, Japan Soc. Mech. Engineering, 1968 